\title{
Development of Late Circadian Preference : Sleep Timing From Childhood to Late Adolescence
}

Kuula, Liisa

2018-03

Kuula , L , Pesonen , A-K, Merikanto , I , Gradisar , M , Lahti , J , Heinonen , K, Kajantie , E \& Räikkönen , K 2018 , ' Development of Late Circadian Preference : Sleep Timing From Childhood to Late Adolescence ' , The Journal of Pediatrics , vol. 194 , pp. 182-+ . https://doi.org/10.1016/j.jpeds.20

http://hdl.handle.net/10138/301087

https://doi.org/10.1016/j.jpeds.2017.10.068

publishedVersion

Downloaded from Helda, University of Helsinki institutional repository.

This is an electronic reprint of the original article.

This reprint may differ from the original in pagination and typographic detail.

Please cite the original version. 


\title{
Development of Late Circadian Preference: Sleep Timing From Childhood to Late Adolescence
}

\author{
Liisa Kuula, MA¹, Anu-Katriina Pesonen, $\mathrm{PhD}^{1}$, Ilona Merikanto, $\mathrm{PhD}^{1}$, Michael Gradisar, $\mathrm{PhD}^{2}$, Jari Lahti, $\mathrm{PhD}^{1,3}$, \\ Kati Heinonen, $\mathrm{PhD}^{1}$, Eero Kajantie, $\mathrm{MD}, \mathrm{PhD}^{4,5,6}$, and Katri Räikkönen, $\mathrm{PhD}^{1}$
}

Objectives To assess differences relating to circadian preference in objectively measured sleep patterns from childhood to adolescence over a 9-year period. We hypothesized there is developmental continuity in sleep timing and duration according to circadian preference.

Study design Young participants ( $N=111,65 \%$ girls) from a community-based birth cohort underwent sleep actigraphy at mean ages $8.1(S D=0.3), 12.3(S D=0.5)$, and $16.9(S D=0.1)$ years. A short version of MorningnessEveningness Questionnaire was administered in late adolescence. At each follow-up, sleep midpoint, duration, wake after sleep onset, sleep efficiency, and weekend catch-up sleep were compared between those reporting morning, intermediate, and evening preferences in late adolescence.

Results Mixed model analyses indicated that sleep timing was significantly earlier among morning types compared with evening types at all ages $(P$ values $<.04)$. The mean differences in sleep midpoint between morning and evening types increased from a mean of 19 minutes (age 8), 36 minutes (age 12), to 89 minutes (age 17). The largest change occurred from age 12 to 17 years. Sleep duration, wake after sleep onset, sleep efficiency, and catch-up sleep did not differ according to circadian preference.

Conclusions This study found significant continuity in sleep timing from childhood to adolescence over 9 years, indicating that late circadian preference reported in late adolescence begins to manifest in middle childhood. Further studies are needed to establish whether sleep timing has its origins at an even earlier age. (J Pediatr 2018;194:182-9).

ircadian preference varies between individuals and is influenced by genetic factors ${ }^{1-3}$ and external cues. ${ }^{4}$ This results in differences in activities such as sleep timing. Later circadian preference is associated with several adverse outcomes. $^{5-8}$

During childhood, sleep timing is highly dependent on parental guidance. This typically changes during adolescence, when more autonomy is gained over schedules. ${ }^{9}$ Together with emerging biological pressure toward a later-timed circadian rhythm, adolescence is a particularly vulnerable period for problems in circadian regulation ${ }^{10,11}$ : several reports emphasize that adolescents have a high risk for developing delayed sleep phase disorder, ${ }^{12}$ as they tend to have the most irregular sleep behavior and a large amount of weekend catch-up sleep compared with other age groups. ${ }^{13}$

Previous cross-sectional studies have reported shorter sleep duration and later sleep midpoint among those who report a preference for eveningness. ${ }^{14-16}$ In this longitudinal study, we investigated how self-reported circadian preference reflects in the developmental trajectories of objectively measured sleep patterns from middle childhood to late adolescence and hypothesized there is significant variation in the trajectories specifically related to sleep duration and its timing. We expected that compared with adolescents with a morning preference, adolescents with a circadian preference toward eveningness would have a later sleep midpoint from middle childhood onwards, resulting in shorter sleep duration over time.

\section{Methods}

Participants were recruited from an urban community-based cohort composed of 1049 healthy singletons born in 1998 in Helsinki, Finland. Details are

$\begin{array}{ll}\text { BMI } & \text { Body mass index } \\ \text { MD } & \text { Mean difference } \\ \text { MEQ } & \text { Morningness-Eveningness Questionnaire } \\ \text { T1 } & \text { Time point } 1 \\ \text { T2 } & \text { Time point } 2 \\ \text { T3 } & \text { Time point } 3 \\ \text { WASO } & \text { Wake after sleep onset }\end{array}$

From the ${ }^{1}$ Department of Psychology and Logopedics, University of Helsinki, Helsinki, Finland; ${ }^{2}$ School of Psychology, Flinders University, Adelaide, Australia; ${ }^{3}$ Helsinki Collegium for Advanced Studies, University of Helsinki, Helsinki, Finland; ${ }^{4}$ Chronic Disease Prevention Unit, National Institute for Health and Welfare, Helsinki; ${ }^{5}$ Children's Hospital, Helsinki University Hospital and University of Helsinki, Helsinki, Finland; and ${ }^{6}$ PEDEGO Research Unit, MRC Oulu, Oulu University Hospital and University of Oulu, Oulu

Supported by The Academy of Finland (1287174), the Juho Vainio Foundation, the Signe and Ane Gyllenberg Foundation, the PsyCo Doctoral Programme of

Psychology, the Sigrid Jusélius Foundation, the

Foundation for Pediatric Research, the Novo Nordisk Foundation, the Emil Aaltonen Foundation, and the Australian Research Council. M.G. received funding from Re-Timer Pty Ltd, is a paid consultant for the Australian Psychological Society and Little Brown Book Company, and owns stock in ResMed. The other authors declare no conflicts of interest.

0022-3476/\$ - see front matter. Crown Copyright $\odot 2017$ Published by Elsevier Inc. All rights reserved.

https://doi.org10.1016/.jpeds.2017.10.068 
described in previous reports. ${ }^{1718}$ The current study builds on objective sleep measurements from 3 time points across 9 years, from age 8 and 12 to age 17 years. Figure 1 (available at www.jpeds.com) illustrates the participation in the follow-ups.

In 2006 (time 1 [T1], at 8 years of age), we invited a subsample of the initial cohort members who had given permission to be included in a follow-up and who were traceable. Because of the original research interests, this subsample was weighted on mothers who consumed more glycyrrhizin (which inhibits placental 11 $\beta$-HSD2 function) in the form of licorice during pregnancy. ${ }^{17}$ In 2009-2011 (time 2 [T2], at 12 years of age), all the initial cohort members $(\mathrm{n}=1049)$ who had given permission to be contacted and whose addresses were traceable were invited to a follow-up, of whom $692(75.2 \%)$ could be contacted by phone (mothers of the adolescents).

In 2014-2015 (time 3 [T3], at 17 years of age), we invited all cohort members who participated at T2 and lived within a $30-\mathrm{km}$ radius from Helsinki to participate in a follow-up. At T3, the Morningness-Eveningness Questionnaire (MEQ) ${ }^{19}$ was administered, resulting in data from 189 adolescents. As the result of missing responses to some of the questions in the full MEQ, we used a previously validated short form of MEQ $(\mathrm{rMEQ})^{20}$ comprising 6 of the 19 items in full MEQ.

Complete sleep actigraphy data from all the 3 measurement points and rMEQ data from T3 were available for 112 adolescents. One participant was excluded from analysis due to sleep midpoint differing over 4 SDs from the mean at T3. Thus, our analytical sample consisted of 111 (64\% females) adolescents who had complete sleep data and information on circadian preference.

The ethics committees of the City of Helsinki Health Department and Children's Hospital in Helsinki University Central Hospital approved the study protocols (HUS 400/E7/05 for T1 and T2; 177/13/03/03/2014 for T3). Informed written child and parent consent were obtained at T1 and T2 and only adolescent consent at T3.

The representativeness of the samples at each time point $\mathrm{T} 1,{ }^{21}$ $\mathrm{T} 2{ }^{22}$ and $\mathrm{T} 3{ }^{16}$ in relation to the original cohort has been reported previously. The sample in this study $(\mathrm{n}=111)$ did not differ from the rest of the participants at T3 $(n=86)$ regarding any of the sleep variables, body mass index (BMI), sex, age, mother's BMI, mother's age at birth, gestational age, maternal alcohol consumption, length at birth, birth weight, pubertal development, or highest education level of the parents. Those in the sample had mothers reporting lower maternal licorice consumption compared with other T3 participants $(P=.03)$. With regard to the initial cohort, there were no differences between the current sample $(\mathrm{n}=111)$ and the rest of the initial cohort $(\mathrm{n}=938)$ in mother's BMI, maternal licorice consumption, maternal alcohol consumption, gestational age, length at birth, and birth weight $(P>.07)$, but current participants were more likely to be girls $(P=.002)$ and had older mothers $(P=.003)$.

\section{Sleep}

Actigraphs are watch-like, wrist-worn devices containing motion accelerometers to measure limb movements. Actigraphy is a widely used objective method used to study sleep-wake patterns in pediatric populations. ${ }^{23}$ We measured sleep duration, quality, and timing using actigraphs (Actiwatch AW4 at T1 and AW7 at T2 and T3; CamNtech Ltd, Cambridge, United Kingdom). All measurements were completed with medium sensitivity and 1-minute epochs. We used the validated Actiwatch algorithm ${ }^{23}$ to detect sleep onset and offset.

Participants were instructed to wear actigraphs for 10 days at T1, T2, and T3 on their nondominant wrists and completed sleep diaries during the measurement period. Actigraphy data were handled as described previously. ${ }^{18}$ Participants were instructed to document all temporary pauses into the sleep log and to report other significant occurrences, such as travel or illness. Nights were excluded from further sleep analyses if (1) the actigraph was not in use; (2) information on bedtimes was missing; (3) the data on reported bedtime indicated that the person was already asleep (suggesting that the bedtime was incorrectly reported); (4) information on waking time was missing and the activity pattern was unclear; or (5) a change in normal life was reported, such as sleepovers, daytime napping, illness, or travel.

Sleep duration, onset, offset, and wake after sleep onset (WASO) were extracted from the data by the software (Actiwatch Activity \& Sleep Analysis versions 5.42 and 7.0; CamNtech Ltd). Sleep efficiency was calculated as the time spent asleep divided by the amount of time in bed, multiplied by 100 (reported as a percentage). Sleep midpoint was defined as the time point when one half of assumed sleep (time in bed) had passed since sleep onset. Sleep onset, offset, and midpoints were calculated for both weekdays and weekends separately. Irregular sleep patterns were operationalized as the amount of catchup sleep during the weekend (calculated as the subtraction of weekday nights' sleep duration from weekend nights' sleep duration), assumed to be an indicator of cumulative sleep debt. ${ }^{12}$ In addition, we calculated differences in mean sleep midpoint, sleep onset, sleep offset, weekend catch-up sleep, sleep duration, WASO, and, sleep efficiency from $\mathrm{T} 1$ to $\mathrm{T} 2$, from $\mathrm{T} 1$ to T3, and from T2 to T3 to study the amount of change in these variables over development.

Circadian preference was assessed at T3 using the 6-item short version of the MEQ. ${ }^{19,20}$ MEQ is a questionnaire that evaluates an individual's preference to perform their daily tasks at a certain time. Questions include both direct questions about a person's circadian preference and descriptions of hypothetical situations in which an individual has to select which time frame would result in optimal performance. As described previously, ${ }^{16}$ we used a rating yielding in a 3-class circadian preference: morning, intermediate, and evening. We used the following cut-off points for the classification of rMEQ types: 5-12 for eveningness, 13-18 for intermediate, and 19-27 for morningness. ${ }^{20}$

Information on age and sex were derived from initial cohort records, and these were controlled for in all analyses. Pubertal development was self-reported with the Pubertal Development Scale ${ }^{24}$ at T2 and T3, as described previously. ${ }^{22}$ The Pubertal Development Scale is a validated, 5-item self-report scale for body hair, growth spurts, skin changes, and men- 
arche and breast development for girls and facial hair and voice change for boys. At T3, a mean value was calculated based on a scale of no changes yet (1) to changes seem complete (4); at T2, the fourth option was omitted due to the participants' young age. BMI was calculated as $\mathrm{kg} / \mathrm{m}^{2}$ via the use of measurements from clinical visits $(\mathrm{T} 1, \mathrm{~T} 2)$ or nurse's home visit (T3). Parental education was self-reported at T2 as described previously ${ }^{25}$ and was used as a proxy for socioeconomic status. These variables were investigated as potential confounders for differences in sleep between morning, intermediate, and evening types.

\section{Statistical Analyses}

We used SPSS version 24.0 for all statistical analyses (IBM SPSS Statistics for Windows, Version 24.0; IBM Corp, Armonk, New York). To avoid multiple comparisons, we used a linear mixed model approach, where at the first step we examined whether the overall level of sleep pattern across time differed across circadian preference, and, second, whether the sleep pattern trajectory developed differently across the time points depending on the circadian preference. Finally, as post-hoc analyses only for the statistically significant outputs from the mixed models, we used ANCOVAs to calculate the mean differences (MDs) between circadian preference types. All analyses are reported with $95 \%$ CIs, and the significance threshold was set at .05 . Covariates included sex and age at the time of sleep measurements.

\section{Results}

Table I presents characteristics of the sample according to circadian preference. There were no significant differences in circadian preference regarding birth weight; socioeconomic status; age at measurement points; $\mathrm{BMI}$ at $\mathrm{T} 1, \mathrm{~T} 2$, and $\mathrm{T} 3$; or pubertal development at T2 and T3 (all $P$ values $>.05$ ). There were no significant sex differences in the circadian preference $(P=.88)$, but girls and boys differed regarding 2 sleep measures: sleep duration at T1 and T3 was significantly longer in girls compared with boys ( $\mathrm{MD}=0: 16$ hours, $95 \%$ CI 0:00$0: 33, P<.04$ and $\mathrm{MD}=0: 18$ hours, $95 \% \mathrm{CI} 0: 03-0: 32, P=.014$, respectively).

Table II (available at www.jpeds.com) lists the mean amount of measured nights: only participants with sleep data from all time points and a minimum of 3 nights ( 2 participants had only weekday nights at $\mathrm{T} 1$ and 5 participants at T3) from at least 2 time points were included. Regarding differences in sleep timing, weekday and weekend nights were analyzed separately. At T1, sleep data were available for 3-4 nights from 1\%, for 5-7 nights from $83 \%$, and for 8-12 nights from $16 \%$. The corresponding percentages were $3 \%, 24 \%$, and $72 \%$ at $\mathrm{T} 2$ and $2 \%, 25 \%$, and, $71 \%$ at $\mathrm{T} 3$, respectively.

Table II presents the raw sleep values in the entire sample and according to the 3 circadian preference types at $\mathrm{T} 1, \mathrm{~T} 2$, and T3. In line with previously reported normative development, ${ }^{13,18,26}$ weekday and weekend sleep duration decreased over the 3 measurement points, sleep quality (as indicated by decreasing WASO minutes and increasing sleep efficiency) improved, the amount of weekend catch-up sleep increased, and both weekday and weekend sleep onset and offset times shifted to later resulting in later sleep midpoints on both weekdays and weekends. In the current study, T3 sleep measures correlated with previous time points' measures as follows: sleep duration $\mathrm{T} 1$ to $\mathrm{T} 3(\mathrm{r}=0.23, P=.02)$, T2 to $\mathrm{T} 3(\mathrm{r}=0.39$, $P=.001)$; WASO T1 to T3 $(\mathrm{r}=0.29, P=.002)$, T2 to T3 $(\mathrm{r}=0.68, P=.001)$; sleep efficiency $\mathrm{T} 1$ to $\mathrm{T} 3(\mathrm{r}=0.32, P=.001)$, T2 to T3 $(\mathrm{r}=0.68, P<.001)$. Sleep midpoint and weekend

Table I. Basic characteristics of the participants at T1, T2, and T3

\begin{tabular}{|c|c|c|c|c|c|c|}
\hline Characteristics & $\begin{array}{c}\text { Evening } \\
\mathrm{N}=\mathbf{2 8}(25.2 \%) \\
\text { Mean (SD) or } \mathrm{n}(\%)\end{array}$ & $\begin{array}{c}\text { Intermediate } \\
\mathrm{N}=66(59.5 \%) \\
\text { Mean (SD) or } \mathrm{n}(\%)\end{array}$ & $\begin{array}{c}\text { Morning } \\
\mathrm{N}=17(15.3 \%) \\
\text { Mean (SD) or } \mathrm{n}(\%)\end{array}$ & $P^{k}$ & $P^{\dagger}$ & $p$ \\
\hline Sex (female) & $18(64.3)$ & $43(65.2)$ & $10(58.8)$ & .63 & .72 & .94 \\
\hline Birth weight, $\mathrm{g}^{\S}$ & $3628(300)$ & 3565 (506) & $3612(471)$ & .73 & .89 & .46 \\
\hline Highest parental education" & & & & .71 & .29 & .12 \\
\hline Secondary or less & $0(0.0)$ & $8(12.1)$ & $1(5.9)$ & & & \\
\hline Vocational & $4(14.3)$ & 12 (18.2) & $4(23.5)$ & & & \\
\hline University degree & $24(85.7)$ & $46(69.7)$ & $12(70.6)$ & & & \\
\hline Age at $\mathrm{T} 1, \mathrm{y}$ & $8.0(0.33)$ & $8.1(0.29)$ & $8.0(0.32)$ & .22 & .89 & .22 \\
\hline Age at T2, y & $12.3(0.60)$ & $12.3(0.52)$ & $12.4(0.54)$ & .34 & .71 & .57 \\
\hline Age at T3, y & $16.9(0.14)$ & $16.9(0.12)$ & $16.9(0.13)$ & .79 & .63 & .29 \\
\hline$\left.\mathrm{BM}\right|^{\star *}$ at $\mathrm{T} 1$ & $16.6(1.69)$ & $16.8(2.08)$ & $16.4(1.50)$ & .47 & .67 & .68 \\
\hline $\mathrm{BMI}^{\star \star}$ at T2 & $19.5(2.55)$ & $19.7(3.11)$ & $19.3(2.79)$ & .66 & .81 & .79 \\
\hline $\mathrm{BMI}^{\star \star}$ at T3 & $22.4(3.00)$ & $21.8(3.62)$ & $21.1(2.46)$ & .45 & .15 & .47 \\
\hline Pubertal development ${ }^{\dagger \dagger}$ at $\mathrm{T} 2$ & $1.83(0.50)$ & $1.92(0.55)$ & $2.08(0.56)$ & .29 & .13 & .48 \\
\hline Pubertal development ${ }^{\dagger \dagger}$ at T3 & $3.28(0.45)$ & $3.32(0.35)$ & $3.27(0.46)$ & .64 & .94 & .68 \\
\hline
\end{tabular}

$P$ values are obtained from $\chi^{2}$ tests for categorical variables and $t$ tests for continuous variables.

${ }^{\star} P$ morning vs intermediate.

$\dagger P$ morning vs evening.

$\ddagger P$ intermediate vs evening.

$\S$ Derived from hospital records.

१Parent-reported at T2.

${ }^{\star \star}$ Calculated as $\mathrm{kg} / \mathrm{m}^{2}$.

††Measured with the Pubertal Development Scale. 
catch-up sleep did not correlate significantly with previous time points' measurements.

\section{Developmental Trajectories of Sleep Patterns According to Circadian Preference}

The mixed model analyses showed that 1 interval toward morningness changed the overall mean of sleep midpoint on all days $(B=-23.82$ minutes, $95 \%$ CI -32.87 to -14.77 ; $P<.001$ ), weekdays ( $B=-24.20$ minutes, $95 \% \mathrm{CI}-35.74$ to $-12.66 ; P<.001)$, and weekends $(\mathrm{B}=-35.81$ minutes, $95 \% \mathrm{CI}$ -54.58 to $-17.04 ; P<.001)$. This was reflected also in later sleep onset, $(\mathrm{B}=-20.89$ minutes, $95 \% \mathrm{CI}-29.80$ to $-11.98 ; P<.001$; $\mathrm{B}=-27.61$ minutes, $95 \% \mathrm{CI}-40.79$ to $-14.44 ; P<.001$, respectively) and offset ( $\mathrm{B}=-17.54$ minutes, $95 \% \mathrm{CI}-28.04$ to
$-7.04 ; P \leq .001 ; \mathrm{B}=-28.87$ minutes, $95 \% \mathrm{CI}-42.83$ to -14.91 ; $P<.001$, respectively) on both weekdays and weekends, respectively. Figures 2-4 illustrate the statistically significant trajectories across time. Sleep duration $(P=.71)$, weekend catchup sleep $(P=.93)$, WASO $(P=.53)$, and sleep efficiency $(P=.70)$ across T1, T2, and T3, were not significantly associated with circadian preference in all days, weekdays, or weekends in the mixed model analyses and were not examined further.

As shown in Figure 2, the post-hoc comparisons at each time point indicated sleep midpoints were 19 (T1), 36 (T2), and 89 (T3) minutes later among the evening types compared with the morning types $(P$ values $<.04)$, and this difference was more emphasized during the weekend nights $(28,55$, and 140 minutes, at the respective time points; $P$ values $<.02)$. During

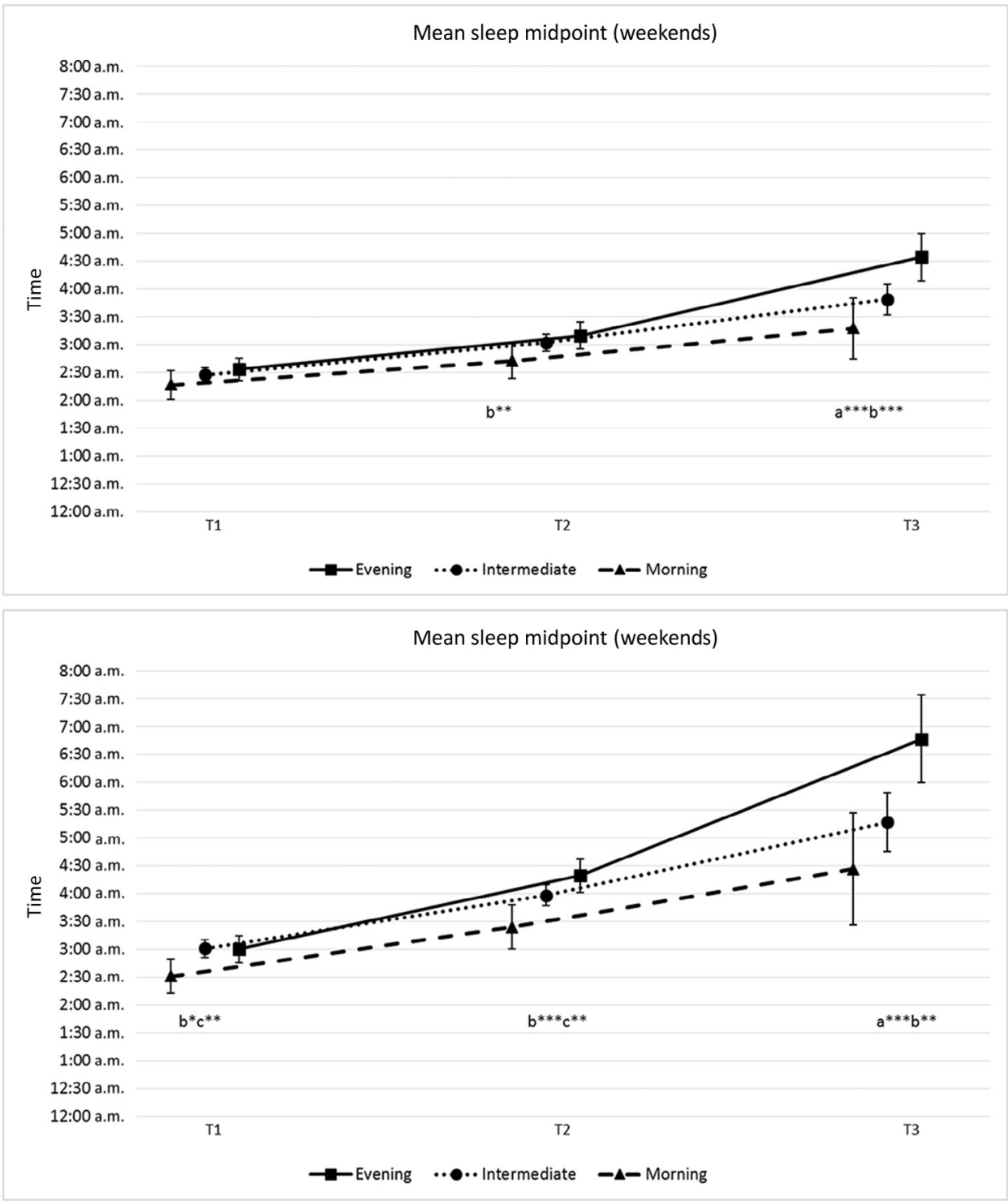

Figure 2. Sleep midpoint at ages 8,12 , and 17 years according to circadian preference at 17 years. Mean measures of sleep midpoint at T1, T2, and T3 according to circadian preference. Bars represent $95 \% \mathrm{Cls}$. MD significance marked: $\mathrm{a}=$ evening vs intermediate type; $\mathrm{b}=$ evening vs morning type; $\mathrm{c}=$ intermediate vs morning type; ${ }^{\star} P<.05,{ }^{\star \star} P<.01{ }^{\star \star \star} P<.001$. 


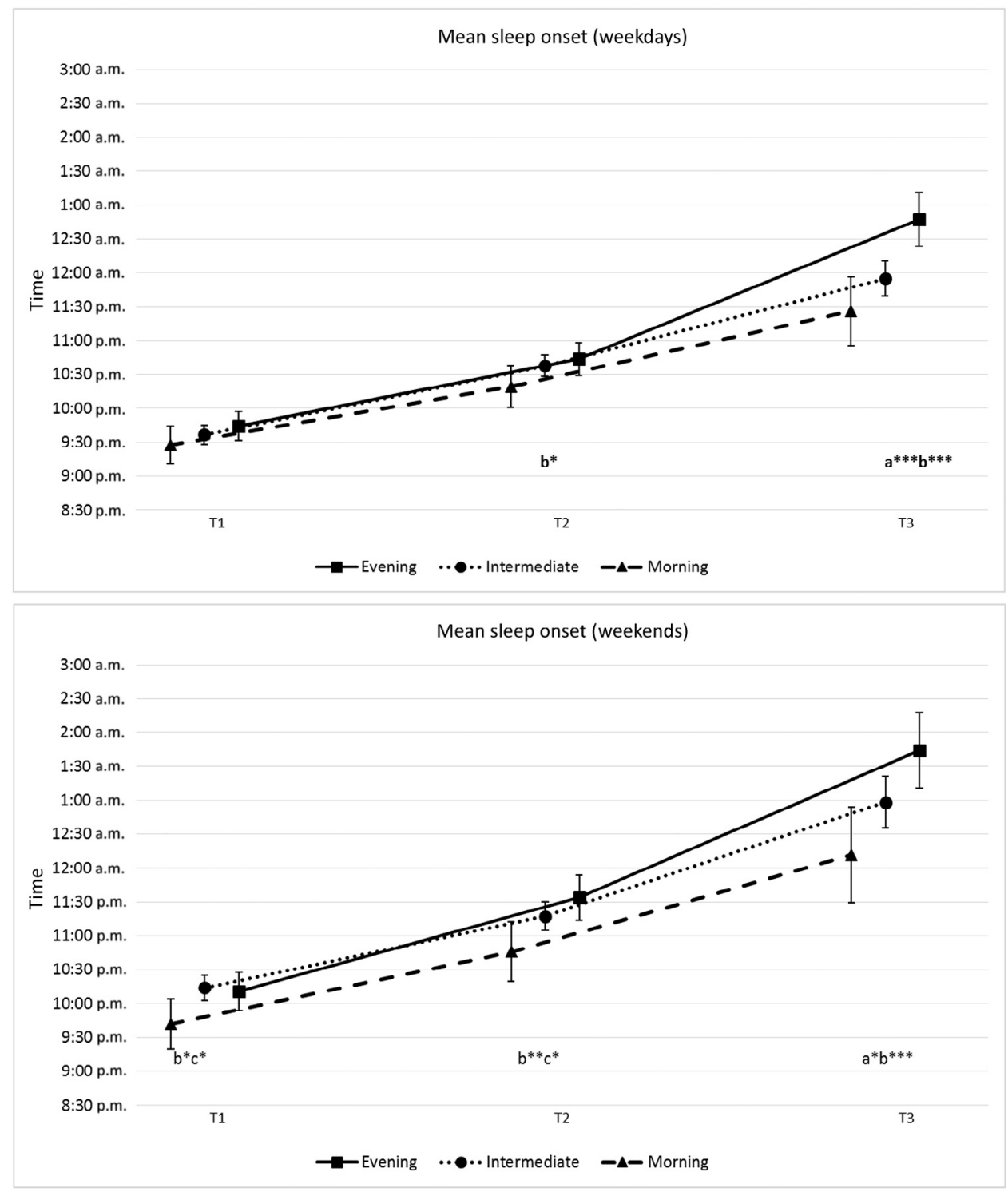

Figure 3. Sleep onset at ages 8, 12, and 17 years according to circadian preference at 17 years. Mean measures of sleep onset at T1, T2, and T3 according to circadian preference. Bars represent $95 \% \mathrm{Cls}$. MD significance marked: a $=$ evening vs intermediate type; $\mathrm{b}=$ evening vs morning type; $\mathrm{c}=$ intermediate vs morning type; ${ }^{\star} P<.05,{ }^{\star \star} P<.01{ }^{\star \star \star} P<.001$.

weekday nights, the differences were significant only at T2 and T3 $(27$ minutes, $P<.02$ and 77 minutes $P<.001$, respectively; 16 minutes at T1, $P=.10)$. In addition, intermediate types had a later sleep midpoint compared with morning types and at weekends at T1 $(P=.01)$, at T2 $(P=.01)$, but not at T3 $(P=.15)$. Later circadian preference was also reflected in significantly later sleep onset (Figure 3 ) and offset (Figure 4) times both during weekdays and weekends.

We detected significant time by circadian preference interactions for sleep midpoint (weekdays $P=.006$; weekends $P=.002$ ), and sleep onset (weekdays $P=.002$; weekends $P<.05)$. Table III shows that MDs in the sleep midpoint from $\mathrm{T} 1$ and T2 to T3 were significantly larger in evening types compared with intermediate and morning types in all days, weekdays, and weekends (mixed model interactions with time in evening vs intermediate type $P=.003 ; P=.018 ; P=.003$; evening vs morning type $P=.008 ; P=.026 ; P=.055$, respectively; $P$ values $>.59$ for morning vs intermediate type).

Furthermore, these differences occurred as a result of evening types' weekday sleep onset times becoming later (mixed model interactions with time in evening vs intermediate type $P=.006$; evening vs morning type $P=.008 ; P$ values $=.44$ for morning vs intermediate type) (Table III).

\section{Discussion}

We examined sleep trajectories from childhood to late adolescence over a period of 9 years with respect to individual circadian preferences in adolescence. Based on objective assessment of sleep timing over 3 measurement points, the data 


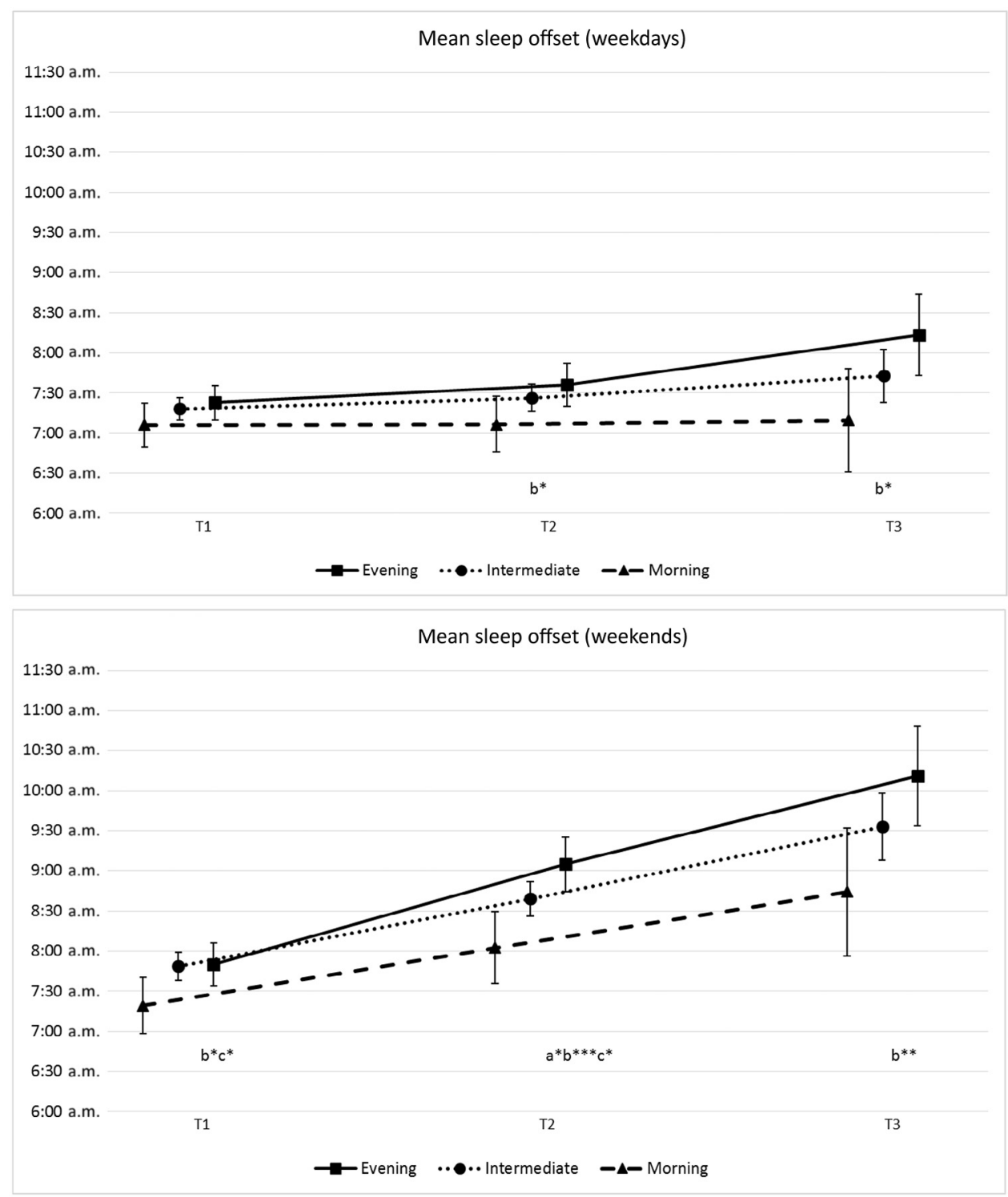

Figure 4. Sleep offset at ages 8,12 , and 17 years according to circadian preference at 17 years. Mean measures of sleep offset at T1, T2, and T3 according to circadian preference. Bars represent $95 \%$ Cls. MD significance marked: $a=$ evening vs intermediate type; $\mathrm{b}=$ evening vs morning type; $\mathrm{c}=$ intermediate vs morning type; ${ }^{\star} P<.05,{ }^{\star \star} P<.01{ }^{\star \star \star} P<.001$.

indicated that sleep timing is established already in childhood and persists over development into late adolescence. $\mathrm{Al}-$ though the difference in sleep midpoint between morning and evening types was only 19 minutes at the age of 8 years, it increased over time, resulting in an MD of 89 minutes at the age of 17 years. The largest change occurred between 12 and 17 years of age.

We did not detect any differences in pubertal status or BMI between the circadian preference types across development. Likewise, sleep duration, quality, or amount of weekend catchup sleep did not differ between the circadian preference types over the transition from middle childhood to late adolescence. This may suggest that our findings related to sleep timing are not a result of any cumulative sleep debt but represent an independent feature of sleep. Similarly, when analyzed in crosssection, adolescent circadian preference was not associated with sleep duration or quality, but only with sleep timing. ${ }^{27}$

Weekend sleep midpoint is likely to be an accurate indicator of the natural circadian preference. ${ }^{11,13,28}$ Already at the age of 8 years, weekend sleep midpoint differed between those who reported a morning preference and those reporting either an intermediate or an evening preference at age 17 years. This would suggest that the morning type is separate from other diurnal preferences already at an early age. However, the developmental changes in sleep timing differed according to circadian preference, with evening types having the greatest changes in sleep midpoint across time points. This may reflect a growing autonomy over sleep schedules. 


\begin{tabular}{|c|c|c|c|c|c|c|}
\hline \multirow[b]{2}{*}{ Sleep timing comparison } & \multicolumn{3}{|c|}{ Change in minutes from $\mathrm{T} 1$ to $\mathrm{T} 2$} & \multicolumn{3}{|c|}{ Change in minutes from T2 to $\mathrm{T} 3$} \\
\hline & MD & $95 \% \mathrm{CI}$ & $P$ & MD & $95 \% \mathrm{Cl}$ & $P$ \\
\hline \multicolumn{7}{|l|}{ Weekday sleep midpoint } \\
\hline Evening-intermediate & -3.1 & $(-21.5$ to 15.2$)$ & .74 & -37.9 & (-73.1 to 2.8$)$ & .035 \\
\hline Evening-morning & -10.7 & $(-35.7$ to 14.3$)$ & .40 & -50.4 & $(-98.1$ to -2.7$)$ & .039 \\
\hline Intermediate-morning & -7.5 & $(-29.8$ to 14.7$)$ & .50 & -12.5 & $(-29.7$ to 54.7$)$ & .56 \\
\hline \multicolumn{7}{|l|}{ Weekday sleep onset } \\
\hline Evening-intermediate & 0.4 & $(-17.7$ to 18.5$)$ & .96 & -46.4 & $(-79.4$ to -13.4$)$ & .006 \\
\hline Evening-morning & -8.3 & $(-33.0$ to 16.3$)$ & .51 & -57.9 & $(-102.8$ to 13.0$)$ & .012 \\
\hline Intermediate-morning & -8.7 & $(-30.6$ to 13.2$)$ & .43 & -11.5 & (-51.2 to 28.2$)$ & .57 \\
\hline \multicolumn{7}{|l|}{ Weekend sleep midpoint } \\
\hline Evening-intermediate & -28.7 & $(-51.9$ to -5.6$)$ & .015 & -75.2 & $(-138.9$ to -11.4$)$ & .021 \\
\hline Evening-morning & -33.1 & $(-65.3$ to -0.8$)$ & .044 & -97.0 & $(-184.9$ to -9.0$)$ & .031 \\
\hline Intermediate-morning & -4.3 & $(-33.0$ to 24.4$)$ & .77 & -21.8 & $(-100.2$ to 56.6$)$ & .58 \\
\hline \multicolumn{7}{|l|}{ Weekend sleep onset } \\
\hline Evening-intermediate & -24.4 & $(-51.3$ to 2.4$)$ & .07 & -32.4 & $(-76.7$ to 11.9$)$ & .15 \\
\hline Evening-morning & -27.7 & $(-65.1$ to 9.7$)$ & .14 & -47.8 & (108.9 to 13.2 ) & .12 \\
\hline Intermediate-morning & -3.3 & $(-36.6$ to 30.0$)$ & .85 & -15.4 & $(-69.8$ to 39.0$)$ & .58 \\
\hline
\end{tabular}

$P$ value represents significance in MD between 2 circadian preference types. Mean values presented in Table II.

Our study was performed in a well-characterized birth cohort with objectively defined sleep patterns. The follow-up period of 9 years covered the educational and developmental pathway from middle childhood to late adolescence. As limitations, the longitudinal sample with data available from all measurement points was considerably smaller than the cross-sectional samples. However, our longitudinal sample did not differ statistically from the rest of the T3 participants and only differed in 2 respects from the initial cohort members (sex and maternal age), somewhat limiting the representativeness of our findings. Second, we had rMEQ information available only for T3 and were thus unable to test temporal stability in the subjective circadian preference.

This longitudinal study demonstrates how differences in sleep patterns according to circadian preference persist from childhood to late adolescence and shows that these preferences are distinguishable already in childhood. The results indicate that the type of an individual's circadian preference, as observed on the verge of adulthood, was established in childhood. In particular, the earlier sleep timing of the morning types stood out most clearly at the first assessment time at 8 years. Although sleep rhythm shifted later in all participants over time, the trajectory toward later sleep was particularly marked in the evening types. Finally, we disclose that poor or irregular sleep may not be risks for developing a late circadian preference. These implications underline the importance of distinguishing circadian preference and sleep timing from other sleep patterns and problems. Although it is likely that several processes influence the development of circadian preference, ${ }^{1-4}$ future replication studies using longitudinal designs will aid in determining the direction of effect.

Submitted for publication Jul 6, 2017; last revision received Oct 20, 2017; accepted Oct 30, 2017

Reprint requests: Liisa Kuula, MA, Department of Psychology and Logopedics, Faculty of Medicine, University of Helsinki, P O Box 21, 00014 Helsinki, Finland. E-mail: liisa.kuula-paavola@helsinki.fi

\section{References}

1. Hu Y, Shmygelska A, Tran D, Eriksson N, Tung JY, Hinds DA. GWAS of 89,283 individuals identifies genetic variants associated with selfreporting of being a morning person. Nat Commun 2016;7:10448.

2. Lane JM, Vlasac I, Anderson SG, Kyle SD, Dixon WG, Bechtold DA, et al. Genome-wide association analysis identifies novel loci for chronotype in 100,420 individuals from the UK Biobank. Nat Commun 2016;7: 10889.

3. Jones SE, Tyrrell J, Wood AR, Beaumont RN, Ruth KS, Tuke MA, et al. Genome-wide association analyses in 128,266 individuals identifies new morningness and sleep duration loci. PLoS Genet 2016;12:e1006125.

4. Duffy JF, Dijk DJ. Getting through to circadian oscillators: why use constant routines? J Biol Rhythms 2002;17:4-13.

5. Wong PM, Hasler BP, Kamarck TW, Muldoon MF, Manuck SB. Social jetlag, chronotype, and cardiometabolic risk. J Clin Endocrinol Metab 2015; 100:4612-20.

6. Wennman H, Kronholm E, Partonen T, Peltonen M, Vasankari T, Borodulin K. Evening typology and morning tiredness associates with low leisure time physical activity and high sitting. Chronobiol Int 2015;32:1090100.

7. Roeser K, Bruckner D, Schwerdtle B, Schlarb AA, Kubler A. Healthrelated quality of life in adolescent chronotypes—a model for the effects of sleep problems, sleep-related cognitions, and self-efficacy. Chronobiol Int 2012;29:1358-65.

8. Zuurbier LA, Luik AI, Hofman A, Franco OH, Van Someren EJ, Tiemeier H. Fragmentation and stability of circadian activity rhythms predict mortality: the Rotterdam study. Am J Epidemiol 2015;181:54-63.

9. Short MA, Gradisar M, Wright H, Lack LC, Dohnt H, Carskadon MA. Time for bed: parent-set bedtimes associated with improved sleep and daytime functioning in adolescents. Sleep 2011;34:797-800.

10. Hagenauer MH, Lee TM. The neuroendocrine control of the circadian system: adolescent chronotype. Front Neuroendocrinol 2012;33:21129.

11. Roenneberg T, Kuehnle T, Pramstaller PP, Ricken J, Havel M, Guth A, et al. A marker for the end of adolescence. Curr Biol 2004;14:R1038-9.

12. Crowley SJ, Acebo C, Carskadon MA. Sleep, circadian rhythms, and delayed phase in adolescence. Sleep Med 2007;8:602-12

13. Gradisar M, Gardner G, Dohnt H. Recent worldwide sleep patterns and problems during adolescence: a review and meta-analysis of age, region, and sleep. Sleep Med 2011;12:110-8.

14. Allebrandt KV, Teder-Laving M, Kantermann T, Peters A, Campbell H, Rudan I, et al. Chronotype and sleep duration: the influence of season of assessment. Chronobiol Int 2014;31:731-40. 
15. Kitamura S, Hida A, Watanabe M, Enomoto M, Aritake-Okada S, Moriguchi Y, et al. Evening preference is related to the incidence of depressive states independent of sleep-wake conditions. Chronobiol Int 2010;27:1797-812.

16. Merikanto I, Pesonen AK, Kuula L, Lahti J, Heinonen K, Kajantie E, et al. Eveningness as a risk for behavioral problems in late adolescence. Chronobiol Int 2017;34:225-34.

17. Strandberg TE, Jarvenpaa AL, Vanhanen H, McKeigue PM. Birth outcome in relation to licorice consumption during pregnancy. Am J Epidemiol 2001;153:1085-8.

18. Pesonen AK, Martikainen S, Heinonen K, Wehkalampi K, Lahti J, Kajantie E, et al. Continuity and change in poor sleep from childhood to early adolescence. Sleep 2014;37:289-97.

19. Horne JA, Ostberg O. A self-assessment questionnaire to determine Morningness Eveningness in human circadian rhythms. Int J Chronobiol 1976;4:97-110.

20. Hatonen T, Forsblom S, Kieseppa T, Lonnqvist J, Partonen T. Circadian phenotype in patients with the co-morbid alcohol use and bipolar disorders. Alcohol Alcohol 2008;43:564-8.

21. Pesonen AK, Raikkonen K, Matthews K, Heinonen K, Paavonen JE, Lahti J, et al. Prenatal origins of poor sleep in children. Sleep 2009;32:108692.
22. Kuula L, Pesonen AK, Martikainen S, Kajantie E, Lahti J, Strandberg T, et al. Poor sleep and neurocognitive function in early adolescence. Sleep Med 2015;16:1207-12.

23. Meltzer LJ, Montgomery-Downs HE, Insana SP, Walsh CM. Use of actigraphy for assessment in pediatric sleep research. Sleep Med Rev 2012;16:463-75.

24. Petersen AC. A self-report measure of pubertal status: reliability, validity, and initial norms. J Youth Adolesc 1988;17:11733 .

25. Pesonen AK, Martikainen S, Kajantie E, Heinonen K, Wehkalampi K, Lahti $J$, et al. The associations between adolescent sleep, diurnal cortisol patterns and cortisol reactivity to dexamethasone suppression test. Psychoneuroendocrinology 2014;49:150-60.

26. Iglowstein I, Jenni OG, Molinari L, Largo RH. Sleep duration from infancy to adolescence: reference values and generational trends. Pediatrics 2003;111:302-7.

27. Tonetti L, Fabbri M, Filardi M, Martoni M, Natale V. Effects of sleep timing, sleep quality and sleep duration on school achievement in adolescents. Sleep Med 2015;16:936-40.

28. Roenneberg T, Kuehnle T, Juda M, Kantermann T, Allebrandt K, Gordijn M, et al. Epidemiology of the human circadian clock. Sleep Med Rev 2007;11:429-38. 


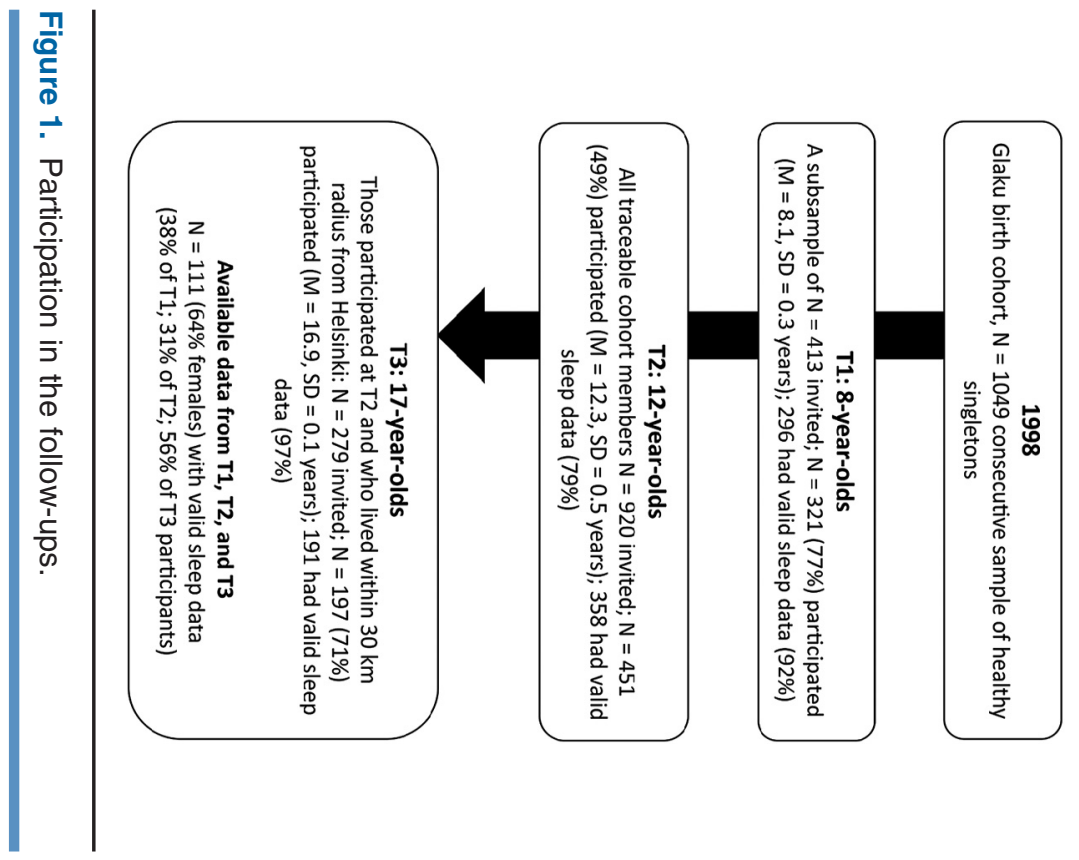

\begin{tabular}{|c|c|c|c|c|c|c|c|c|c|c|c|c|}
\hline \multirow[b]{2}{*}{ Sleep characteristics } & \multicolumn{3}{|c|}{ All } & \multicolumn{3}{|c|}{ Evening type } & \multicolumn{3}{|c|}{ Intermediate type } & \multicolumn{3}{|c|}{ Morning type } \\
\hline & $\begin{array}{c}\mathrm{T} 1 \\
\text { Mean (SD) }\end{array}$ & $\begin{array}{c}\text { T2 } \\
\text { Mean (SD) }\end{array}$ & $\begin{array}{c}\mathrm{T} 3 \\
\text { Mean (SD) }\end{array}$ & $\begin{array}{c}\mathrm{T} 1 \\
\text { Mean (SD) }\end{array}$ & $\begin{array}{c}\mathrm{T} 2 \\
\text { Mean (SD) }\end{array}$ & $\begin{array}{c}\mathrm{T3} \\
\text { Mean (SD) }\end{array}$ & $\begin{array}{c}\mathrm{T} 1 \\
\text { Mean (SD) }\end{array}$ & $\begin{array}{c}\mathrm{T} 2 \\
\text { Mean (SD) }\end{array}$ & $\begin{array}{c}\mathrm{T} 3 \\
\text { Mean (SD) }\end{array}$ & $\begin{array}{c}\mathrm{T} 1 \\
\text { Mean (SD) }\end{array}$ & $\begin{array}{c}\mathrm{T} 2 \\
\text { Mean (SD) }\end{array}$ & $\begin{array}{c}\mathrm{T} 3 \\
\text { Mean (SD) }\end{array}$ \\
\hline Measured nights, $n$ & $6.9(1.2)$ & $8.1(1.6)$ & $8.2(1.8)$ & $7.3(1.1)$ & $7.8(2.0)$ & $8.2(1.6)$ & $6.9(1.4)$ & $8.1(1.5)$ & $8.0(1.9)$ & $7.0(0.8)$ & $8.7(1.0)$ & $9.3(1.2)$ \\
\hline Sleep midpoint, all days, time & 2:35 (0:32) & $3: 15(0: 38)$ & $4: 21(1: 30)$ & $2: 39(0: 30)$ & $3: 27(0: 36)$ & $5: 01(1: 36)$ & 2:37 (0:23) & 3:16 (0:40) & 4:16 (1:31) & $2: 18(0: 31)$ & 2:53 (0:24) & $3: 34(0: 35)$ \\
\hline Sleep midpoint, weekdays, time & $2: 26(0: 33)$ & $3: 00(0: 39)$ & $4: 00(1: 29)$ & $2: 32(0: 27)$ & $3: 10(0: 39)$ & $4: 33(1: 36)$ & $2: 27(0: 35)$ & 3:01 (0:40) & 3:57 (1:30) & $2: 14(0: 28)$ & $2: 43(0: 23)$ & $3: 19(0: 40)$ \\
\hline Sleep midpoint, weekend, time & $2: 56(0: 40)$ & 3:58 (0:48) & $5: 38(2: 25)$ & $2: 59(0: 42)$ & $4: 19(0: 38)$ & $6: 45(3: 30)$ & $3: 01(0: 37)$ & 3:57 (0:49) & $5: 26(1: 54)$ & $2: 29(0: 43)$ & $3: 24(0: 40)$ & 4:29 (0:58) \\
\hline Sleep onset, weekday, time & $21: 37(0: 35)$ & 22:36 (0:39) & $0: 03(1: 09)$ & $21: 43(0: 32)$ & $22: 44(0: 40)$ & $0: 47(1: 26)$ & $21: 37(0: 37)$ & $22: 37(0: 41)$ & $23: 54(0: 59)$ & $21: 25(0: 33)$ & $22: 20(0: 26)$ & $23: 28(0: 38)$ \\
\hline Sleep onset, weekend, time & 22:08 (0:46) & $23: 17(0: 52)$ & $1: 02(1: 35)$ & $22: 10(0: 48)$ & $23: 34(0: 45)$ & $1: 40(1: 56)$ & $22: 14(0: 43)$ & $23: 16(0: 56)$ & 0:59 (1:29) & $21: 40(0: 46)$ & $22: 47(0: 37)$ & 0:13(0:44) \\
\hline Sleep c & $7: 17(0: 35)$ & $7: 25(0: 43)$ & 7:45 (1:22) & $7: 21(0: 27)$ & 7:36 (0:45) & 8:11 $(1$ & $7: 19(0: 39)$ & & & 7:03 (0:28) & & $7: 10(0: 49)$ \\
\hline Sleep offset, weekend, time & $7: 44(0: 45)$ & $8: 40(0: 56)$ & $9: 35(1: 45)$ & $7: 48(0: 43)$ & 9:05 (0:40) & $10: 06(2: 00)$ & $7: 49(0: 44)$ & $8: 39(0: 57)$ & $9: 34(1: 38)$ & 7:16 (0:47) & $8: 00(0: 53)$ & $8: 45(1: 21)$ \\
\hline Catch-up sleep at weekend, min & $-0: 01(0: 37)$ & $0: 29(0: 47)$ & $0: 41(1: 12)$ & $0: 01(0: 36)$ & $0: 36(0: 35)$ & $0: 49(1: 30)$ & $-0: 03(0: 37)$ & $0: 29(0: 52)$ & $0: 37(1: 06)$ & $0: 03(0: 40)$ & $0: 18(0: 44)$ & $0: 42(1: 03)$ \\
\hline Sleep duration, all days, $h$ & $8: 24(0: 41)$ & $7: 57(0: 25)$ & 7:05 (0:37) & $8: 26(0: 43)$ & $8: 02(0: 28)$ & $7: 00(0: 39)$ & $8: 21(0: 41)$ & $7: 56(0: 24)$ & $7: 09(0: 37)$ & $8: 33(0: 41)$ & $7: 53(0: 27)$ & 7:01 (0:35) \\
\hline Sleep duration, weekdays, $\mathrm{h}$ & 8:25 (0:42) & 7:49 (0:28) & $6: 55(0: 43)$ & $8: 25(0: 43)$ & $7: 53(0: 32)$ & 6:46 (0:52) & 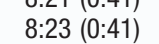 & $7: 48(0: 26)$ & 6:59 (0:38) & $8: 32(0: 47)$ & $7: 48(0: 32)$ & $6: 52(0: 42)$ \\
\hline Sleep duration, weekend, $h$ & $\begin{array}{l}0.25(0.4<) \\
8: 23(0: 49)\end{array}$ & $8: 18(0: 45)$ & $\begin{array}{l}0.53(0.43) \\
7: 36(1: 04)\end{array}$ & $\begin{array}{l}8.25(0.4) \\
8: 27(0: 53)\end{array}$ & $\begin{array}{l}7.53(0.32) \\
8: 26(0: 32)\end{array}$ & $\begin{array}{l}\text { r.40 (1.52) } \\
\text { 7:36 (1:01) }\end{array}$ & $\begin{array}{l}8: 19(0: 50) \\
8: 50\end{array}$ & $\begin{array}{l}7.48(0.20) \\
8: 18(0: 49)\end{array}$ & $\begin{array}{l}7.37(1: 08) \\
7: .09\end{array}$ & $\begin{array}{l}8.32(0.47) \\
8: 35(0: 39)\end{array}$ & $\begin{array}{l}7.40(0.54) \\
8: 04(0: 43)\end{array}$ & $\begin{array}{l}0.32(0.42) \\
7: 35(0: 55)\end{array}$ \\
\hline & $1: 14(0: 32)$ & $1: 00(0: 20)$ & $0: 50(0: 20)$ & $1: 12(0: 35)$ & $0: 59(0: 18)$ & $0: 47(0: 15)$ & $1: 17(0: 30)$ & $1: 01(0: 22)$ & $0: 50(0: 21)$ & 1:04 (0:35) & $1: 00(0: 17)$ & $0: 51(0: 20)$ \\
\hline Sleep efficiency (\%), all days & $\begin{array}{l}84.0(6.1) \\
\end{array}$ & $\begin{array}{l}8.3(4.3) \\
85.3(4.20)\end{array}$ & $86.4(4.6)$ & $84.1(6.7)$ & $\begin{array}{l}85.6(3.9) \\
85.6\end{array}$ & $\begin{array}{l}86.9(3.4) \\
86\end{array}$ & $83.4(5.7)$ & $\begin{array}{l}85.1(4.6) \\
85)\end{array}$ & $86.2(5.0)$ & $\begin{array}{l}1.04(0.06) \\
86.3(6.2)\end{array}$ & $85.7(3.8)$ & $86.5(4.7)$ \\
\hline
\end{tabular}

